\title{
Effect of Chronic Potassium Loading on Potassium
}

\section{Secretion by the Pars Recta or Descending}

\section{Limb of the Juxtamedullary Nephron in the Rat}

\author{
Carlos A. Battilana, Dennis C. Dobyan, Frank B. Lacy, Jahar Bhattacharya, \\ Paul A. Johnston, and Rex L. Jamison, Division of Nephrology, Stanford \\ University School of Medicine, Stanford, California 94305
}

\begin{abstract}
A B S T RACT Recently we demonstrated potassium secretion by the pars recta or by the descending limb of the juxtamedullary nephron. The purpose of this present investigation is to study the effect of a chronic high-potassium intake on this phenomenon. Fractional reabsorption of water and sodium by the juxtamedullary proximal nephron was decreased when compared to that in normal hydropenic rats. There was a striking increase in the fraction of filtered potassium at the end of the juxtamedullary descending limb from $94 \pm 11 \%$ to $180 \pm 18 \%$, which was principally a result of enhanced potassium secretion. When the concentration of potassium in the collecting tubule fluid of potassium-loaded rats was reduced after the administration of amiloride, a sharp fall was observed in the amount of potassium which reached the end of the descending limb $(64 \pm 8 \%)$. A direct correlation was observed between the fraction of filtered potassium at the end of the descending limb and the potassium concentration in the final urine $(P<0.001)$. The findings suggest that potassium, like urea, normally undergoes medullary recycling, which is enhanced by chronic potassium loading.
\end{abstract}

Portions of this work were presented to the Ninth American Society of Nephrology, 1976; to the Tenth American Society of Nephrology, 1977; and to the Western Society for Clinical Research, 1977. Clin. Res. 25: 165A. (Abstr.)

Dr. Johnston was a Fellow of the Bay Area Heart Association. His present address is: Division of Nephrology, Department of Medicine, Boston University School of Medicine, Boston, Mass. 02215. Dr. Battilana was a Fellow of the National Kidney Foundation. His present addres is: Avda Javier Prado 3220, San Borja, Lima, Peru. Dr. Bhattacharya was a Fellow of the Dean's Fellowship Fund, Stanford University. His present address is: Department of Medicine, University of California School of Medicine, San Francisco, Calif. 94122. Dr. Dobyan is a recipient of U. S. Public Health Service Research Fellowship 1 F32-AM 05741-01. During a portion of this study, Dr. Jamison was a Fellow of the John Simon Guggenheim Foundation.

Received for publication 19 October 1977 and in revised form 10 July 1978.

\section{INTRODUCTION}

We recently reported that potassium is normally secreted by the pars recta or by the descending limb of the juxtamedullary nephron (1). ("Juxtamedullary" is used here to mean nephrons with long loops of Henle.) The purpose of this present investigation is to study the effect of a chronic high-potassium intake on this phenomenon because potassium loading augments secretion of potassium elsewhere in the renal tubule $(2,3)$. The results demonstrate that potassium secretion by the juxtamedullary nephron is substantially increased. Furthermore, a very good correlation was found between the fraction of filtered potassium which remained at the end of the juxtamedullary descending limb in the exposed left renal papilla and the urinary fractional excretion of potassium from the right (unexposed) kidney. To distinguish cause and effect in this correlation, amiloride was administered to potassium-loaded rats. Amiloride inhibition of potassium secretion in the distal and collecting tubule downstream was associated with a sharp fall in the fraction of filtered potassium remaining upstream in the juxtamedullary descending limb. To account for these findings, we propose that in the renal medulla, potassium is reabsorbed by the collecting tubule and secreted into the juxtamedullary descending limb or pars recta; that is, potassium, like urea, normally undergoes medullary recycling, a process which is enhanced by chronic potassium loading.

\section{METHODS}

52 young Munich-Wistar rats of either sex which weighed 80-125 g were divided into five groups:

Group 1: Potassium-loaded rats, micropuncture of Henle's loop and vasa recta. 13 rats were potassium-loaded as follows: seven rats were given a liquid diet with a high potassium content $(0.38 \mathrm{mmol} \mathrm{KCl} / \mathrm{ml})$ for at least 7 days before the day of micropuncture. Six rats were fed a high-potassium pellet $\operatorname{diet}(2 \mathrm{mmol} \mathrm{KCl} / \mathrm{g}$ ) (ICN Pharmaceuticals, Inc., Life Sciences 
Group, Cleveland, Ohio) for the same length of time. In preliminary studies, six rats were placed in individual metabolic cages to assess the effectiveness of potassium loading as determined by urinary excretion of potassium per $24 \mathrm{~h}$. Three rats were fed the liquid diet and three rats the solid diet. The average daily potassium intake was $\cong 20$ meq with either diet.

The day of micropuncture, the animals were anesthetized with Inactin (Byk Gulden-Lomberg Chemische Fabrik gmbH, Konstanz, West Germany) (100 mg/kg body wt) and the left renal papilla exposed by methods previously described (4). Urine from the unexposed right kidney was collected through a bladder catheter. The animals were infused at $0.03 \mathrm{ml} / \mathrm{min}$ with $0.9 \%$ saline which contained inulin at a concentration sufficient to maintain the plasma inulin concentration between 80 and $100 \mathrm{mg} / 100 \mathrm{ml}$. Samples were obtained by micropuncture of the descending limb near the bend of Henle's loop and from adjacent vasa recta. The collection technique for loop fluid and vasa recta plasma, and the criteria established before beginning the experiments for acceptable collections were identical to those previously described (5).

Group 2: Normal hydropenic control rat. 18 Munich-Wistar rats were fed regular rat chow $(0.13 \mathrm{mmol} \mathrm{KCl} / \mathrm{g})$. Urinary and plasma data and electrolyte concentrations in loop fluid and plasma from vasa recta for group 2 rats were previously reported (5). Micropuncture experiments were performed with a protocol similar to that for group 1.

Group 3: Chronically water-loaded rats. Seven rats were placed in individual metabolic cages, fed regular rat chow, and given $10 \%$ dextrose in water to drink until their daily urine volumes equalled those of potassium-loaded rats. Micropuncture experiments were performed with a protocol similar to that for group 1 except that no vasa recta samples were obtained.

Group 4: Potassium-loaded rats, micropuncture of collecting duct. Seven rats were fed a high potassium diet for at least 7 days. Samples were obtained from the base and tip of a collecting duct of the left kidney with the dorsal exposure of the papilla recently described by Stein et al. (6) instead of the usual ventral approach. ("Base" refers to the region of the exposed papilla adjacent to the main body of the kidney.) Heavier rats were selected for this group to ensure a maximum length of exposed papilla.

Group 5: Amiloride-infused, potassium-loaded rats, loop of Henle and collecting duct micropuncture. Seven rats were prepared according to the protocol used in group $4.45 \mathrm{~min}$ before micropuncture began, a loading dose of amiloride ( 1 $\mathrm{mg} / \mathrm{kg}$ body wt) was administered intravenously, followed by a maintenance dose $(0.4 \mathrm{mg} / \mathrm{kg}$ body $\mathrm{wt} / \mathrm{min})$ of amiloride which was dissolved in normal saline and infused at a constant rate of $0.03 \mathrm{ml} / \mathrm{min}$. Samples were obtained from the end of the descending limb and from the base and tip of a collecting tubule.

The osmolality and concentrations of sodium, potassium, and inulin of loop fluid, vasa recta plasma, urine from the right kidney, and femoral arterial plasma were determined by methods previously described (7).

Values in vasa recta plasma were corrected for plasma water, assuming a vasa recta plasma protein concentration of $7 \mathrm{~g} / 100$ $\mathrm{ml}(5,8)$. Because the electrolyte concentrations in loop fluid and vasa recta plasma are in part determined by the osmolality of the medullary interstitium, the electrolyte composition of loop fluid from control rats and of vasa recta samples from both control and potassium-loaded rats was normalized with respect to the mean osmolality of loop fluid in potassiumloaded rats according to the following equation (5):

$$
\mathrm{E}_{1}=\frac{\mathrm{Osm}_{1}}{\mathrm{Osm}_{2}} \cdot \mathrm{E}_{2}
$$

where $E_{1}=$ corrected electrolyte concentration of loop fluid or vasa recta plasma; $E_{2}=$ uncorrected electrolyte concentration of loop fluid or vasa recta plasma; $\mathrm{Osm}_{1}=$ mean loop fluid osmolality in potassium-loaded rats; and $\mathrm{Osm}_{2}=$ osmolality of the corresponding $\mathrm{E}_{2}$ sample.

Statistical analysis between groups was done with Student's $t$ test for comparing two independent means. The difference in electrolyte concentrations between loop fluid and vasa recta plasma was analyzed with Student's $t$ test for paired determinations. A regression analysis was performed by the least squares' method (9).

\section{RESULTS}

Comparison of potassium-loaded rats (group 1) with normally-fed rats (group 2). In rats fed the liquid or solid high-potassium diet, a steady-state of high-potassium intake and excretion was reached well before the 7 th day. The potassium output was $21 \pm 1.7 \mathrm{meq}$ (liquid diet) and $19 \pm 0.7 \mathrm{meq}$ (solid diet) the 6 th day, and urinary flow was $63 \pm 8.5 \mathrm{ml} / 24 \mathrm{~h}$ and $58 \pm 6.9 \mathrm{ml} / 24 \mathrm{~h}$, respectively. The high urinary flow rates are presumed a result of the increased osmotic excretory load of potassium chloride.

Some parameters of arterial blood and right kidney function are presented in Tables I and II. There were no significant differences in mean blood pressure, hematocrit, and plasma sodium concentration between potassium-loaded and control rats. The mean plasma potassium concentration in potassium-loaded rats was higher than that in normal hydropenic rats. Glomerular filtration rate (GFR) ${ }^{1}$ urinary osmolality, and urine-tosystemic plasma $(U / P)$ inulin in potassium-loaded rats were lower than the respective values in control rats.

The composition of loop fluid and fractional delivery of solute are shown in Tables III and IV. The tubule fluid-to-systemic plasma (TF/P) inulin in potassiumloaded rats was lower than that in control rats. There were no significant differences in $\mathrm{TF} / \mathrm{P}$ osmolality or $\mathrm{TF} / \mathrm{P}$ sodium. Although the mean $\mathrm{TF} / \mathrm{P}$ potassium in potassium-loaded rats was higher than that in control rats, the difference was not statistically significant. The ([TF/ $\mathrm{P}$ potassium]:[TF/ $\mathrm{P}$ sodium]) ratio in potassiumloaded rats, however, significantly exceeded that in control rats, which indicates that fractional delivery of potassium relative to that of sodium was higher in potassium-loaded rats. The percentage of filtered load of potassium ([TF/P potassium]:[TF/ $\mathrm{P}$ inulin]) $\times 100$, in potassium-loaded rats, $180 \pm 18 \%$, was almost double that in normal rats. The value is significantly higher than $100 \%(P<0.001)$, which is unequivocal evidence for potassium secretion (i.e., net potassium addition) by the juxtamedullary nephron proximal to the hairpin turn.

A comparison of electrolyte concentrations in Henle's

\footnotetext{
${ }^{1}$ Abbreviations used in this paper: GFR, glomerular filtration rate; TF/P, tubule fluid-to-systemic plasma; U/P, urine-tosystemic plasma.
} 
TABLE I

Values for Arterial Blood and Right Kidney Function

\begin{tabular}{|c|c|c|c|c|c|}
\hline & $\begin{array}{l}\text { Chronic } \\
\text { potassium- } \\
\text { loaded } \\
\text { (group 1) }\end{array}$ & $\begin{array}{c}\text { Normal } \\
\text { hydropenic } \\
\text { (group 2) }\end{array}$ & $\begin{array}{c}\text { Chronic } \\
\text { water-loaded } \\
\text { (group 3) }\end{array}$ & $\begin{array}{l}\text { Chronic } \\
\text { potassium- } \\
\text { loaded- } \\
\text { collecting duct } \\
\text { micropuncture } \\
\text { (group 4) }\end{array}$ & $\begin{array}{c}\text { Chronic } \\
\text { potassium } \\
\text { loading } \\
\text { and amiloride } \\
\text { infusion; } \\
\text { collecting duct } \\
\text { and loop } \\
\text { micropuncture } \\
\text { (group 5) }\end{array}$ \\
\hline$n$ & 13 & 18 & 7 & 7 & 7 \\
\hline \multicolumn{6}{|l|}{ Arterial blood (plasma) } \\
\hline Blood pressure, $\mathrm{mm} / \mathrm{hg}$ & $93 \pm 2$ & $92 \pm 2$ & $97 \pm 4$ & $95 \pm 1$ & $89 \pm 4$ \\
\hline Hematocrit & $40 \pm 1$ & $40 \pm 1$ & $44 \pm 1$ & $42 \pm 1$ & $39 \pm 2$ \\
\hline Sodium, meq/liter & $150 \pm 1$ & $149 \pm 1$ & $149 \pm 1$ & $148 \pm 2$ & $145 \pm 2 *$ \\
\hline Potassium, meq/liter & $5.3 \pm 0.2$ & $4.4 \pm 0.1 \ddagger$ & $4.9 \pm 0.2$ & $5.3 \pm 0.1$ & $8.2 \pm 0.5 \S$ \\
\hline \multicolumn{6}{|l|}{ Right kidney function } \\
\hline Urine flow, $\mu \mathrm{l} / \mathrm{min} / \mathrm{g}$ kidney $w t$ & $6.0 \pm 0.6$ & $4.5 \pm 0.3$ & $4.8 \pm 0.4$ & $10.5 \pm 0.9 \S$ & $9.8 \pm 1.3 \ddagger$ \\
\hline GFR, $\mu \mathrm{l} / \mathrm{min} / \mathrm{g}$ kidney $u t$ & $826 \pm 37$ & $1,120 \pm 40 \S$ & $1,095 \pm 81^{\prime \prime}$ & $1,314 \pm 106$ & $810 \pm 50$ \\
\hline Osmolality, mosmol/kg $\mathrm{H}_{2} \mathrm{O}$ & $1,101 \pm 23$ & $1,720 \pm 74 \S$ & $1,505 \pm 102 \S$ & $1,352 \pm 82$ & $1,199 \pm 29^{\prime \prime}$ \\
\hline $\mathrm{U} / \mathrm{P}$ inulin & $153 \pm 18$ & $252 \pm 23 \S$ & $229 \pm 15^{*}$ & $129 \pm 12$ & $89 \pm 9^{\prime \prime}$ \\
\hline FE sodium, \% & $0.2 \pm 0.0$ & $0.2 \pm 0.1$ & $0.1 \pm 0.0$ & $0.1 \pm 0.0$ & $2.8 \pm 0.3 \S$ \\
\hline FE potassium, \% & $38 \pm 5$ & $22 \pm 2^{\pi}$ & $19 \pm 3^{*}$ & $61 \pm 4$ & $19 \pm 2 *$ \\
\hline \multicolumn{6}{|l|}{ Weights } \\
\hline Body wt, $g$ & $93 \pm 4$ & $93 \pm 2$ & $106 \pm 6^{\prime \prime}$ & $121 \pm 4 \S$ & $112 \pm 8^{\prime \prime}$ \\
\hline \multicolumn{6}{|l|}{ Kidney wt } \\
\hline Left, $g$ & $0.51 \pm 0.03$ & $0.43 \pm 0.00$ & $0.49 \pm 0.03$ & $0.73 \pm 0.06 \S$ & $0.65 \pm 0.05^{*}$ \\
\hline Right, $g$ & $0.51 \pm 0.04$ & $0.41 \pm 0.02$ & $0.50 \pm 0.03$ & $0.72 \pm 0.05 \S$ & $0.63 \pm 0.06^{\prime \prime}$ \\
\hline
\end{tabular}

Values are means \pm SE. FE, fractional excretion (percent of filtered load). In this table, data from groups $2,3,4$, and 5 are compared with corresponding data in group 1. There were also some significant differences among the other groups, but for the sake of clarity concerning the principal findings, these differences are not indicated in this table. A complete tabulation follows in Table II. Footnote symbols indicate $P$ values significantly different compared to the corresponding values in group 1 .

$* P<0.025$.

$\$ P<0.01$.

$\$ P<0.001$.

" $P<0.05$.

$P<0.005$

TABLE II

Statistical Comparison (P Values) between Groups: Values for Arterial Blood and Right Kidney Function

\begin{tabular}{lccccccccccc}
\hline & 1 vs. 2 & 1 vs. 3 & 1 vs. 4 & 1 vs. 5 & 2 vs. 3 & 2 vs. 4 & 2 vs. 5 & 3 vs. 4 & 3 vs. 5 & 4 vs. 5 \\
\hline Blood pressure & NS & NS & NS & NS & NS & NS & NS & NS & NS & $<0.02$ \\
Hematocrit & NS & NS & NS & NS & $<0.025$ & $<0.05$ & NS & NS & $<0.05$ & NS \\
Plasma Na & NS & NS & NS & $<0.025$ & NS & NS & $<0.025$ & NS & NS & NS \\
Plasma K & $<0.01$ & NS & NS & $<0.001$ & NS & $<0.01$ & $<0.001$ & NS & $<0.001$ & $<0.001$ \\
Urine flow & NS & NS & $<0.001$ & $<0.01$ & NS & $<0.001$ & $<0.001$ & $<0.001$ & $<0.005$ & NS \\
GFR & $<0.001$ & $<0.05$ & $<0.005$ & NS & NS & $<0.05$ & $<0.001$ & NS & $<0.025$ & $<0.005$ \\
Osmolality & $<0.001$ & $<0.001$ & NS & $<0.05$ & NS & $<0.01$ & $<0.001$ & NS & $<0.025$ & NS \\
U/P inulin & $<0.001$ & $<0.025$ & NS & $<0.025$ & NS & $<0.001$ & $<0.001$ & $<0.001$ & $<0.001$ & $<0.02$ \\
FE Na & NS & NS & NS & $<0.001$ & NS & NS & $<0.001$ & NS & $<0.001$ & $<0.001$ \\
FE K & $<0.005$ & $<0.025$ & $<0.005$ & $<0.025$ & NS & $<0.001$ & NS & $<0.001$ & NS & $<0.001$ \\
Body wt & NS & $<0.05$ & $<0.001$ & $<0.05$ & $<0.005$ & $<0.001$ & $<0.005$ & NS & NS & NS \\
Left kidney wt & NS & NS & $<0.001$ & $<0.05$ & $<0.005$ & $<0.001$ & $<0.001$ & $<0.005$ & $<0.05$ & NS \\
Right kidney wt & NS & NS & $<0.001$ & $<0.025$ & $<0.025$ & $<0.001$ & $<0.001$ & $<0.005$ & $<0.05$ & NS \\
\hline
\end{tabular}

FE, fractional excretion (percent of filtered load). 
TABLE III

Composition of Fluid from End of Descending Limb

\begin{tabular}{lcccc}
\hline & $\begin{array}{c}\text { Chronic potassium- } \\
\text { loaded (group 1) }\end{array}$ & $\begin{array}{c}\text { Normal hydropenic } \\
\text { (group 2) }\end{array}$ & $\begin{array}{c}\text { Chronic water-loaded } \\
\text { (group 3) }\end{array}$ & $\begin{array}{c}\text { Chronic potassium-loaded, } \\
\text { amiloride infusion (group 5) }\end{array}$ \\
\hline TF/P inulin & $3.9 \pm 0.2$ & $6.7 \pm 0.5^{*}$ & $6.9 \pm 0.6^{*}$ & $6.9 \pm 1.2 \ddagger$ \\
TF/P osmolality & $2.6 \pm 0.2$ & $3.0 \pm 0.1$ & $2.5 \pm 0.2$ & $2.5 \pm 0.1$ \\
TF/P sodium & $2.1 \pm 0.2$ & $2.3 \pm 0.1$ & $1.9 \pm 0.2$ & $1.9 \pm 0.1$ \\
TF/P potassium & $7.1 \pm 0.7$ & $5.8 \pm 0.5$ & $4.2 \pm 0.8 \S$ & $3.8 \pm 0.3 \ddagger$ \\
TF/P potassium/TF/P sodium & $3.6 \pm 0.4$ & $2.5 \pm 0.1^{\prime \prime}$ & $2.2 \pm 0.3^{\Uparrow}$ & $2.0 \pm 0.2 \S$ \\
& & & \\
Fraction of filtered load remaining at end of descending limb & & $45 \pm 9 \S$ \\
Total solute & $69 \pm 4$ & $46 \pm 3^{*}$ & $42 \pm 7^{\prime \prime}$ & $33 \pm 6^{\prime \prime}$ \\
Sodium & $57 \pm 4$ & $39 \pm 3 \ddagger$ & $31 \pm 6 \ddagger$ & $64 \pm 8^{*}$ \\
Potassium & $180 \pm 18$ & $94 \pm 11^{*}$ & $66 \pm 14^{*}$ & \\
\hline
\end{tabular}

Values are means \pm SE. In this table, data from groups 2, 3, and 5 are compared with corresponding data in group 1. There were also significant differences among the other groups, but for the sake of clarity they are not indicated in this table. A complete tabulation follows in Table IV. Footnote symbols indicate $P$ values significantly different compared to the corresponding values in group 1 .

$* P<0.001$.

$\$ P<0.005$.

$\S P<0.025$.

" $P<0.01$.

ก $P<0.05$.

loop fluid with that of vasa recta plasma is presented in Table $\mathrm{V}$. The uncorrected and corrected potassium concentration of loop fluid and the corrected vasa recta plasma potassium concentration in potassium-loaded rats were higher than the respective values in loop fluid or vasa recta plasma of control rats (Table V).

Comparison of potassium-loaded rats (group 1) with water-loaded rats (group 3). Group 3 animals were used to exclude nonspecific effects as a result of the copious urinary flow induced by the large osmotic load of potassium chloride. As shown in Tables I and II, the mean arterial blood pressure, hematocrit, plasma sodium, and potassium concentrations in chronically water-loaded rats did not differ significantly from corresponding values for potassium-loaded rats. The GFR,
U/P inulin, and urinary osmolality in chronically waterloaded rats were greater than the respective values in potassium-loaded rats. Urinary excretion of potassium was less in chronically water-loaded rats than in potassium-loaded rats.

The TF/P inulin of loop fluid in chronically waterloaded rats exceeded that in potassium-loaded rats (Tables III and IV). No significant differences in TF/P sodium and $\mathrm{TF} / \mathrm{P}$ osmolality were observed between the two groups, but the TF/P potassium in chronically water-loaded rats was lower than that in potassiumloaded rats. The percentage of filtered sodium reaching the end of the juxtamedullary descending limb was less in chronically water-loaded rats than in the potassium-loaded group. The most striking finding, however,

TABLE IV

Statistical Comparison (P Values) between Groups: Composition of Fluid from End of Descending Limb

\begin{tabular}{lcccccc}
\hline & 1 vs. 2 & 1 vs. 3 & 1 vs. 5 & 2 vs. 3 & 2 vs. 5 & 3 vs. 5 \\
\hline TF/P inulin & $<0.001$ & $<0.001$ & $<0.005$ & NS & NS & NS \\
TF/P osmolality & NS & NS & NS & NS & $<0.05$ & NS \\
TF/P sodium & NS & NS & NS & $<0.025$ & $<0.01$ & NS \\
TF/P potassium & NS & $<0.025$ & $<0.005$ & NS & $<0.05$ & NS \\
TF/P potassium/TF/P sodium & $<0.01$ & $<0.05$ & $<0.025$ & NS & NS & NS \\
Fraction of filtered solute remaining & $<0.001$ & $<0.01$ & $<0.025$ & NS & NS & NS \\
Fraction of filtered sodium remaining & $<0.005$ & $<0.005$ & $<0.01$ & NS & NS & NS \\
Fraction of filtered potassium remaining & $<0.001$ & $<0.001$ & $<0.001$ & NS & NS & NS \\
\hline
\end{tabular}


TABLE V

Sodium and Potassium Concentrations in Loop Fluid and Vasa Recta Plasma

\begin{tabular}{lccccc}
\hline & \multicolumn{2}{c}{ Group 1 } & & \multicolumn{2}{c}{ Group 2 } \\
\cline { 2 - 3 } \cline { 5 - 6 } & $\begin{array}{c}\text { Chronic } \\
\text { potassium-loaded }\end{array}$ & $\begin{array}{c}\text { Normal- } \\
\text { ized }\end{array}$ & & $\begin{array}{c}\text { Normal } \\
\text { hydropenic }\end{array}$ & Normalized* \\
\hline$n$ & 9 & & 18 & \\
Descending limb fluid, meq/liter & & & & $344 \pm 12$ & $303 \pm 9$ \\
$\quad$ Sodium & $332 \pm 31$ & $332 \pm 31$ & & $26 \pm 2 \S$ & $23 \pm 2^{\prime \prime}$ \\
$\quad$ Potassium & $36 \pm 5$ & $36 \pm 5$ & & $938 \pm 37$ & \\
$\quad$ Osmolality, mosmol/kg $\mathrm{H}_{2} \mathrm{O}$ & $818 \pm 66$ & & & $304 \pm 12$ & $265 \pm 11$ \\
Vasa recta plasma, meq/kg $\mathrm{H}_{2} \mathrm{O} \ddagger$ & $316 \pm 33$ & $309 \pm 33$ & & $36 \pm 2$ & $32 \pm 2 \S$ \\
$\quad$ Sodium & $43 \pm 6$ & $46 \pm 7$ & & $936 \pm 34$ & \\
$\quad$ Potassium & $866 \pm 44$ & & &
\end{tabular}

Values are means $\pm \mathrm{SE}$.

* Samples were normalized to isosmolality with group 1 loop fluid osmolality by calculations described in Methods.

$\$$ Conversion to $\mathrm{meq} / \mathrm{kg} \mathrm{H}_{2} \mathrm{O}$ assuming a vasa recta plasma protein concentration of 7 $\mathrm{g} / 100 \mathrm{ml}(5)$.

Footnote symbols indicate $P$ values significantly different from corresponding values in group 1 .

$\S P<0.05$.

" $P<0.005$.

is that the percentage of filtered potassium remaining at the end of the descending limb in chronically waterloaded rats was one-third that of potassium-loaded rats.

Group 4 (potassium-loaded rats, micropuncture of collecting duct). These rats were studied in an attempt to determine the source of the potassium secreted into the pars recta or descending limb (Discussion). The direction and magnitude of net transtubular potassium movement across the papillary collecting duct was assessed by comparing samples of collecting duct fluid obtained at the base of the papilla with those obtained at the tip. To insure maximum exposure of papilla, and therefore maximum length of papillary collecting duct accessible to micropuncture, heavier rats were selected and a dorsal approach through a flank incision (6) was employed, rather than the standard ventral approach through a midline incision. (The dorsal aspect of the exposed papilla is longer than its ventral aspect.) The blood pressure, hematocrit, and plasma sodium and potassium concentrations in groups 1 and 4 were similar (Tables I and II). GFR was greater; urinary osmolality and urinary excretion of potassium were slightly higher as well.

Analyses of collecting tubule fluid are summarized in Table VI. There was a significant rise in TF/P osmolality and TF/P inulin; the latter reflects net water reabsorption equivalent to $0.9 \%$ of GFR. Net reabsorption of total solute and sodium also occurred. These values are essentially similar to those reported previously from this laboratory for normal hydropenic rats (4). The fraction of filtered potassium in collecting tubule fluid at the base of the exposed papilla (68\%) was not significantly different from that excreted $(71 \%)$; i.e., on the average, there was no detectable net transtubular movement of potassium across the exposed segment of papillary collecting tubule in the potassium-loaded rats.

Group 5 (potassium-loaded rats, infusion of amiloride). These experiments represent another approach to determining the source of potassium secreted by the pars recta or by the descending limb of the juxtamedullary nephron (Discussion). Before administration of amiloride, the mean plasma potassium concentration (not shown) was 5.4 meq/liter, which is similar to that in groups 1 and 4; after amiloride, plasma potassium reached high levels (Tables I and II). U/P inulin was significantly lower in this group than in any of the other four groups. Fractional excretion of potassium was strikingly reduced while that of sodium was increased substantially.

The micropuncture data (Tables III and IV) presumably reflect the diuretic-induced reduction in extracellular fluid volume. Thus the higher mean TF/P inulin and reduced fraction of filtered sodium which remain suggest increased salt and water reabsorption in the juxtamedullary proximal tubule. The TF/P potassium and $T F / P$ potassium-to- $T F / P$ sodium ratios were significantly reduced. The fraction of the filtered load of potassium remaining $(64 \pm 8 \%)$ was sharply decreased to one-third of that in potassium-loaded rats.

As shown in Table VI, when the values at the tip of the collecting duct are compared with the values at the base, there are no significant changes observed, 
TABLE VI

Micropuncture of the Collecting Duct

\begin{tabular}{|c|c|c|c|c|c|c|}
\hline & \multicolumn{3}{|c|}{$\begin{array}{l}\text { Chronic potassium-loaded } \\
\quad(\text { group 4) }(n=7)\end{array}$} & \multicolumn{3}{|c|}{$\begin{array}{l}\text { Chronic potassium-loaded, amiloride } \\
\text { infusion (group 5) }(n=7)\end{array}$} \\
\hline & Base & Tip & $P$ & Base & Tip & $P$ \\
\hline $\mathrm{TF} / \mathrm{P}$ inulin & $47 \pm 6$ & $77 \pm 9$ & $<0.001$ & $47 \pm 8$ & $71 \pm 12$ & $<0.025$ \\
\hline TF/P osmolality & $2.2 \pm 0.1$ & $3.1 \pm 0.1$ & $<0.001$ & $2.1 \pm 0.1$ & $2.4 \pm 0.2$ & NS \\
\hline $\mathrm{TF} / \mathrm{P}$ sodium & $0.60 \pm 0.0$ & $0.33 \pm 0.1$ & $<0.05$ & $1.5 \pm 0.1^{*}$ & $1.3 \pm 0.1^{*}$ & NS \\
\hline TF/P potassium & $28 \pm 3$ & $51 \pm 3$ & $<0.001$ & $7.3 \pm 2.0^{*}$ & $6.1 \pm 1.0 *$ & NS \\
\hline
\end{tabular}

Fraction of filtered load remaining, \%

\begin{tabular}{lcccccc} 
Solute & $5.3 \pm 0.7$ & $4.1 \pm 0.6$ & $<0.05$ & $5.6 \pm 1.3$ & $3.8 \pm 0.5$ & NS \\
Sodium & $1.5 \pm 0.2$ & $0.5 \pm 0.2$ & $<0.001$ & $4.2 \pm 1.2 \ddagger$ & $2.2 \pm 0.4 \S$ & NS \\
Potassium & $68 \pm 12$ & $71 \pm 8$ & NS & $16 \pm 3^{*}$ & $10 \pm 2^{*}$ & NS \\
Water & $2.3 \pm 0.2$ & $1.4 \pm 0.4$ & $<0.001$ & $2.9 \pm 0.9$ & $1.7 \pm 0.3$ & NS \\
\hline
\end{tabular}

Values are means $\pm \mathrm{SE}$. The mean distance between base and tip was $1.6 \pm 0.0 \mathrm{~mm}$ in group 4 and $1.7 \pm 0.0 \mathrm{~mm}$ in group $5 . P$ values in the separate columns refer to paired comparisons between base and tip. Footnote symbols indicate $P$ values significantly different compared to the corresponding values in group 4 .

$* P<0.001$.
$\ddagger P<0.025$.
$\S P<0.005$.

except for the rise in $\mathrm{TF} / \mathrm{P}$ inulin. When the values in group 5 are compared with corresponding values in group 4, the TF/P sodium at the base and tip in group 5 are higher, and the fraction of the filtered load of sodium which remains at the base and tip in group 5 is also higher. In sharp contrast, the fraction of filtered load of potassium remaining at the base and tip in group 5 (16 and $10 \%$, respectively), is much lower than in group 4 (68 and $71 \%$, respectively).

Correlation of fraction of filtered potassium in end descending limb fluid with urinary potassium. The fraction of filtered potassium at the end of the descending limb in groups 1-3 was plotted as a function of fractional excretion of potassium in the urine from the right kidney. The results, shown in Fig. 1, reveal a very good correlation $(y=18.9+3.7 x ; r=0.8 .1 ; P$ $<0.001)$. When the results of the amiloride-treated rats (group 5) are combined with groups 1-3, a similar correlation is observed (Fig. 1). Amiloride, like furosemide (1), decreased the fraction of filtered potassium in loop fluid, but, unlike furosemide, reduced urinary excretion of potassium (Fig. 1). A finding common to both amiloride- and furosemide-treated rats, however, is a significantly lower urinary potassium concentration. Therefore, the fraction of potassium remaining in loop fluid (dependent variable) was plotted against urinary potassium concentration (independent variable) in the two diuretic groups as well as in groups 1-3 (Fig 2). Again a good correlation is observed, but in contrast in Fig. 1, the results from the furosemide-treated rats are

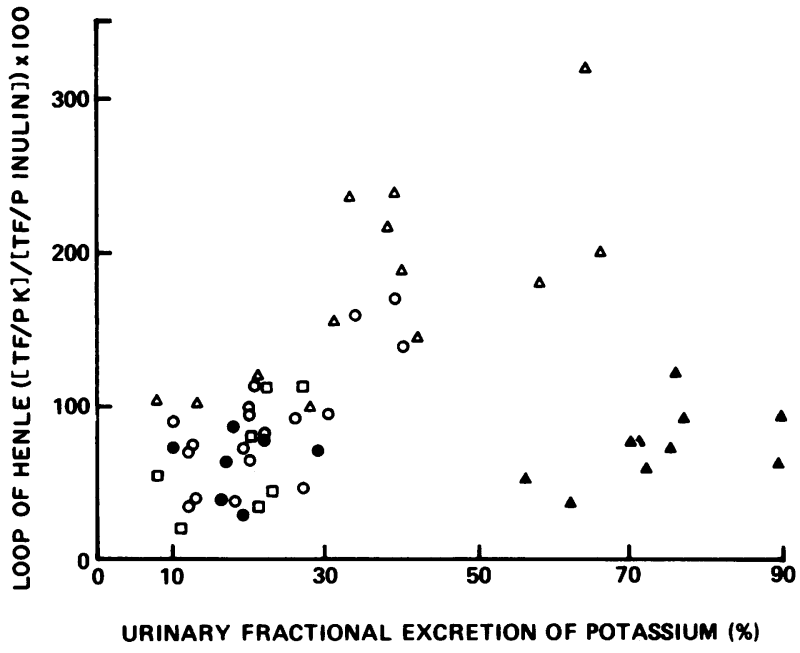

FIGURE 1 The fraction of filtered potassium remaining in fluid at the end of the juxtamedullary descending limb, $([\mathrm{TF} / \mathrm{P}, \mathrm{K}] /[\mathrm{TF} / \mathrm{P}$, inulin] $] \times 100$, as a function of urinary fraction excretion of potassium. Symbols as follows: open triangles, potassium-loaded rats (group 1); open circles, normally-fed rats (group 2); open squares, water-loaded rats (group 3); closed circles, potassium-loaded rats given amiloride (group 5); and closed triangles, normally-fed rats given furosemide (published previously, [1]). Data from groups 1-3, open symbols, demonstrate a clear correlation $(y=18.9+3.7 x ; r=0.81 ; P<0.001)$. Data from group 5 are indistinguishable from those of groups $1-3$. In contrast, while furosemide decreased the fraction of filtered potassium remaining in loop fluid, it increased urinary excretion of potassium. 


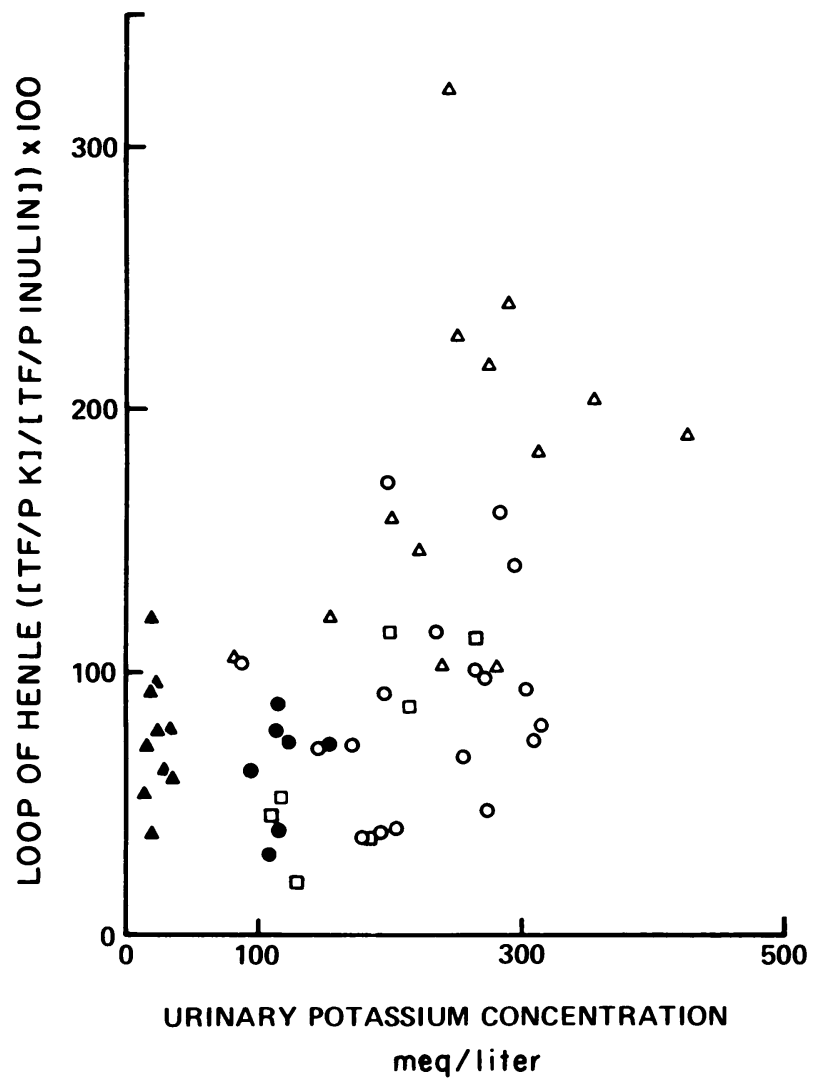

FIGURE 2 The fraction of filtered potassium remaining in fluid at the end of the juxtamedullary descending limb, $([\mathrm{TF} / \mathrm{P}, \mathrm{K}] /[\mathrm{TF} / \mathrm{P}$, inulin $]) \times 100$, as a function of urinary potassium concentration. Symbols are the same as those used in Fig. 1. There is a clear correlation $(y=42.4+0.34 x ; r=0.50$; $P<0.001$ )

indistinguishable from those of the other groups $(y=42.4+0.34 x ; r=0.50 ; P<0.001)$.

\section{DISCUSSION}

The complicated course by which potassium entering the kidney in arterial blood reaches the final urine has been the subject of several recent reviews $(2,3,10)$ and a symposium (11). This present study suggests a new pathway: potassium is reabsorbed from collecting tubule fluid and reenters the juxtamedullary nephron in either its pars recta or descending limb segment. Medullary recycling of potassium appears to be present under normal conditions and is augmented by chronic potassium loading.

Having previously demonstrated potassium secretion by the pars recta or by the descending limb of the juxtamedullary nephron (1), we studied rats fed a highpotassium diet to assess its effects on this phenomenon. Two unavoidable experimental limitations are ap- parent: $(a)$ the use of anesthesia and $(b)$ the inaccessibility of most nephrons and most of the collecting tubule system to micropuncture. Unanesthetized rats ingesting a high-potassium diet excreted 20 meq potassium $/ 100$ g body wt per day, which represents $\cong 2.5$ times their estimated filtered load of potassium. (Assuming the GFR was $1 \mathrm{ml} / 100 \mathrm{~g}$ body wt per min [4], the calculated filtered load of potassium in the unanesthetized potassium-loaded rats $=7.6 \mathrm{meq} / \mathrm{day}$. If average total excretion is $20 \mathrm{meq} / \mathrm{day}$, excretion is 2.6 times the filtered load.) When anesthetized, similarly fed rats excreted only $38-61 \%$ of their filtered load of potassium (Tables I and II), results similar to those reported by others (12). At least two factors impair potassium excretion during anesthesia: low urinary flow and decreased extracellular fluid volume. Urinary flow from the right kidney during anesthesia averaged $6 \mu \mathrm{l} / \mathrm{min}$ per $g$ kidney wt, or about $15 \%$ of the urinary flow in unanesthetized potassium-loaded rats. Because tubule fluid flow rate, particularly in the distal nephron, influences net potassium secretion $(2,3,10-13)$, the antidiuretic state undoubtedly reduced urinary excretion of potassium. The second factor to compromise potassium excretion, recently elucidated by Maddox et al. (14), and confirmed by us (15), is the combination of anesthesia and surgery necessary to prepare rats for micropuncture, which may reduce intravascular and extracellular fluid volume by as much as $20 \%$. As a consequence, proximal sodium reabsorption will be enhanced (16) and distal potassium secretion diminished $(2,3,10,11,17,18)$.

Despite these limitations, a new finding clearly emerges from this study: during chronic high-potassium intake, fractional delivery of potassium to the juxtamedullary end-descending limb is increased sharply from $94 \%$ to $180 \%$, which reflects an increase in potassium secretion by the pars recta or by the descending limb (Tables III and IV). The data from this present study, shown in Fig. 1, reveal a very good correlation between the fraction of filtered potassium at the end of the descending limb and urinary fractional excretion of potassium. Assuming that it is not fortuitous, the correlation implies a causal relationship between the two variables, but does not distinguish cause and effect. Either the increased urinary excretion of potassium is the result of the increased potassium remaining in descending limb fluid or it is the cause thereof. These two interpretations are illustrated in Fig. 3. The first hypothesis (Fig. 3A) may be stated as follows: A mechanism exists whereby potassium in the interstitium of the renal medulla is secreted into the pars recta or the descending limb of the juxtamedullary nephron, which increases the mass flow of potassium that reaches the hairpin turn. Somewhere in the ascending limb, potassium is reabsorbed and then secreted directly into collecting tubule fluid, thereby augmenting overall uri- 


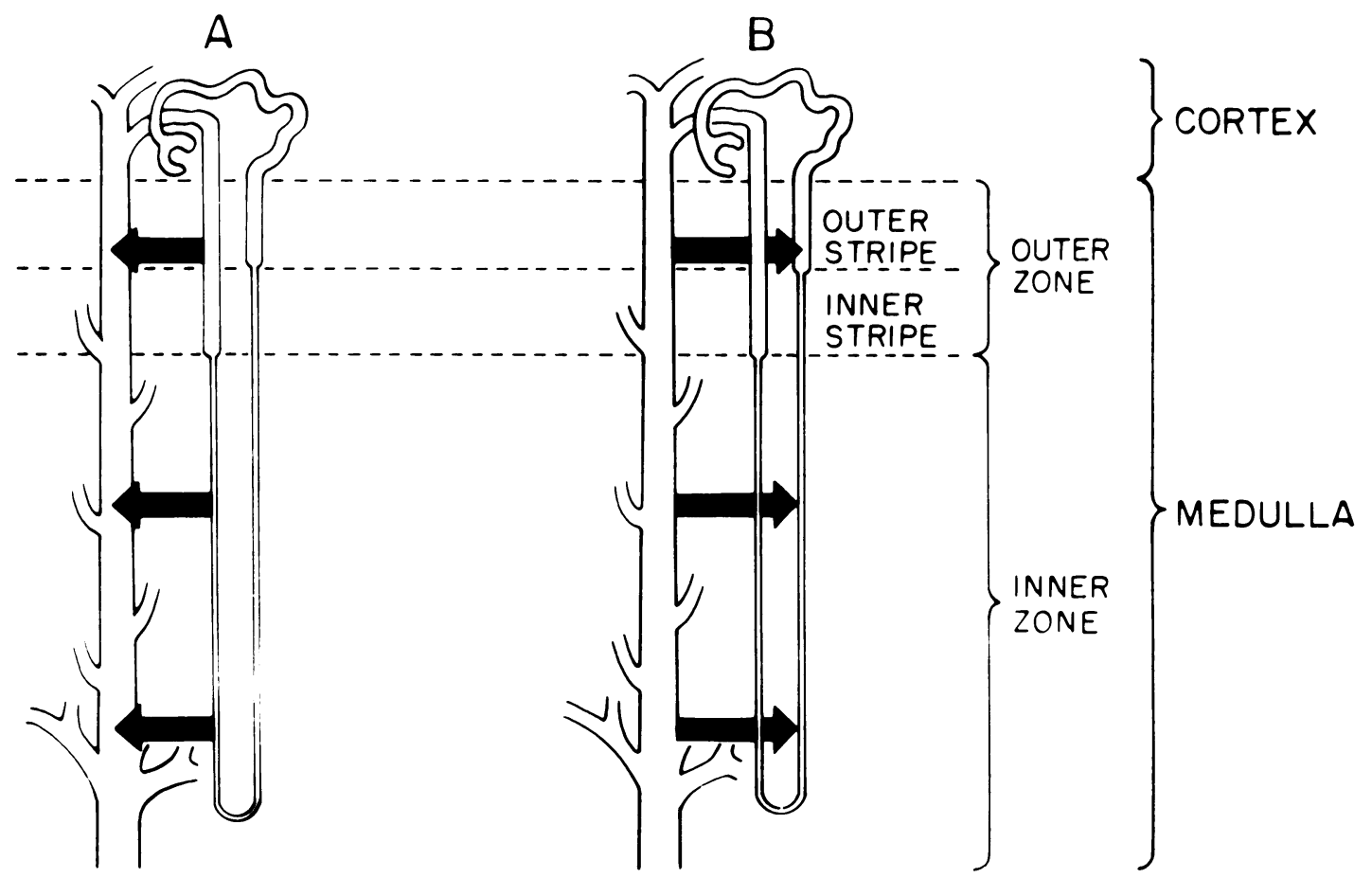

Figure 3 Two hypotheses for potassium movement in the renal medulla. In both A and B, a juxtamedullary nephron is depicted on the right side of a single collecting tubule with its branches. According to hypothesis A, potassium supplied to the medullary interstitium from vasa recta plasma is secreted into either the pars recta or the descending limb of the juxtamedullary nephron, thereby increasing the flow of potassium reaching the hairpin turn. Potassium is reabsorbed either by the thin or thick ascending limb and then secreted directly into collecting tubule fluid, thereby augmenting overall urinary excretion of potassium. ${ }^{2}$ According to hypothesis $\mathrm{B}$, in contrast, potassium is reabsorbed by the collecting tubule and secreted into the pars recta or the descending limb of the juxtamedullary nephron. ${ }^{2}$ For further discussion, please see text.

nary excretion of potassium. ${ }^{2}$ According to the second hypothesis (Fig. 3B), the collecting tubule has a finite permeability to potassium, or actively reabsorbs po-

\footnotetext{
${ }^{2}$ Hypothesis A implies transfer of potassium from the vasculature to the pars recta or to the descending limb by way of the interstitium, and then transfer from the ascending limb to the collecting duct through the interstitium. This need not necessarily be the same interstitium; one may be spatially separate from the other (19). Still another possibility not depicted in Fig. $3 \mathrm{~A}$ is that potassium secreted into the pars recta or the descending limb from the vasculature is not reabsorbed by the ascending limb and, instead, is delivered directly to the collecting tubule via the juxtamedullary distal tubule (Discussion).

The illustration of hypothesis B (Fig. 3B) (transfer of potassium from collecting duct to descending limb) does not indicate what happens to potassium in the intervening interstitium or its fate once it is added to the pars recta or the descending limb. Hypothesis B implies that most of the potassium reaching the medullary interstitium from the collecting tubule is trapped there by countercurrent exchange in vasa recta and then secreted into the pars recta or the descending limb. Hypothesis B also implies that some of the potassium
}

tassium. As more potassium is delivered to the collecting tubule, more potassium is reabsorbed by that segment and then secreted into the pars recta or into the descending limb. ${ }^{2}$

To distinguish between these two hypotheses, the experiments described in groups 4 and 5 were performed. If potassium secreted into the pars recta or the descending limb of the juxtamedullary nephron is a source of potassium for secretion into collecting tubule fluid (Fig. 3A), an increase in potassium remaining in the collecting tubule fluid between base and tip of the exposed papilla (i.e., net potassium addition) should be detected. If the alternative hypothesis (Fig. 3B) is correct, net removal of potassium by the collecting tubule in the exposed papilla should be observed. As shown in Table IV, however, neither addition nor re-

secreted into the pars recta or the descending limb is not reabsorbed by the ascending limb and is delivered directly to the collecting tubule via the juxtamedullary distal tubule (Discussion). 
absorption was consistently demonstrable. This inconsistency has been previously reported by our laboratory (4) and by Diezi et al. (20) and may be a result of an insufficient length of collecting tubule accessible to micropuncture in the exposed papillary tip.

It appeared that the key region of the collecting tubule in which either secretion or reabsorption occurred must lie upstream in the inaccessible portion of the collecting tubule system, i.e., somewhere in the cortex, outer medulla, or inaccessible region of the inner medulla. (We include the cortical collecting tubule here for completeness, although it seems unlikely that potassium is reabsorbed in this segment normally [21].) Therefore, the experiments in group 5 were performed, based on the rationale that if the collecting tubule is the source of potassium destined for secretion in the pars recta or in the descending limb (Fig. 3B), then reducing the mass flow of potassium in the collecting tubule should decrease potassium available for secretion into the juxtamedullary nephron, thereby causing the fraction of potassium which remains at the end of the descending limb to fall. On the other hand, if loop fluid is a source of potassium secreted by the collecting tubule (Fig. 3A), then reducing the amount of potassium reaching the collecting tubule should not decrease the filtered load of potassium at the end-descending limb, because potassium secretion upstream in the pars recta or the descending limb should not be diminished by a reduction in potassium flow downstream in the collecting tubule.

Amiloride was selected for the purpose of reducing potassium flow in the collecting tubule. It was assumed that the drug has no direct effect on potassium secretion by the pars recta or the descending limb, or on potassium reabsorption by the proximal tubule, in accord with in vitro $(21)$ and in vivo $(22,23)$ studies, except that by Deetjen (24) who reported a rise in endproximal TF/P inulin associated with a marked decline in GFR, which he attributed to intratubular precipitation of amiloride in the distal nephron. Although we cannot exclude intratubular blockade, the fact that GFR in amiloride-treated potassium-loaded rats (group 5) was the same as in potassium-loaded rats not given the drug (group 1) indicates that it could not have been extensive. In addition, in potassium-loaded rats, the passage time of an intravenous bolus of a dye, FDC Blue, when measured from glomeruli to end-accessible proximal tubules and from glomeruli to loops to Henle in the exposed renal papilla, did not increase after amiloride administration (unpublished observations). Finally, the decrease in the fraction of sodium $(24 \%)$ and water (14\%) remaining at the end of the descending limb in the amiloride-treated rats represents only a small portion of the $116 \%$ fall in potassium remaining at the same site (Tables III and IV).
As shown in Table I, amiloride had the expected natriuretic effect and profound inhibition of potassium excretion in chronically potassium-loaded rats. The same effects were observed in the collecting tubule of the exposed kidney (Table VI), and agree well with the recent report of Stein et al. (25). With these results in mind, the findings presented in Table III for the amiloride-treated rats clearly distinguish between the two hypotheses in Fig. 3. The fraction of filtered potassium at the end-descending limb in potassiumloaded animals was reduced nearly threefold to $64 \pm 8 \%$, as predicted by hypothesis " $B$ ".

If hypothesis $B$ is correct, and if potassium reabsorption by the collecting tubule is influenced by the transtubular difference in potassium concentration between collecting tubule urine and medullary interstitium, then one might expect to find a correlation between the fraction of filtered potassium at the end of descending limb and urinary potassium concentration. Data in the present experiments plus those observed after administration of furosemide (1), are plotted in Fig. 2 and demonstrate a good correlation. ${ }^{3}$ (Furosemide-induced changes in medullary blood flow might also alter potassium addition to the pars recta or to the descending limb).

In summary, the hypothesis which accounts for the findings in all five groups and the relationships depicted in Figs. 1 and 2 is that potassium is reabsorbed by the collecting tubule somewhere between its origin in the cortex and the terminal papillary segment (presumably in the medullary collecting tubules), and regains entry into the juxtamedullary nephron by secretion either into the pars recta or the descending limb of the juxtamedullary nephron (Fig. 3B).

Role of medullary potassium recycling. The physiological implications of potassium recycling are unclear partly since what happens to potassium between hairpin turn and juxtamedullary distal tubule is unknown. Because the electrochemical gradient appears unfavorable for potassium reabsorption from the thin ascending limb (Table V) and (5, 26, 27), and because a recent study by Burg and Bourdeau (28) suggests potassium secretion may predominate in the initial portion of the cortical thick-ascending limb, some of the potassium added to the juxtamedullary pars recta or the descending limb may conceivably reach the collecting tubule.

The suggestion that potassium undergoes medullary recycling is not intended to exclude potassium secre-

\footnotetext{
${ }^{3}$ In our previous paper (1), we also reported that benzolamide caused an increase in the fraction of filtered potassium remaining at the end of the juxtamedullary descending limb. These data are not shown in Figs. 1 or 2 because the effect of benzolamide on potassium reabsorption in the proximal tubule is uncertain.
} 
tion by the collecting tubule, for which there is considerable evidence $(2,12,13,18,25,29-34)$. The variability between potassium remaining in the late distal tubule fluid and that in the urine $(12,13,18,24,33,34)$, and even between base and tip of the exposed papillary collecting tubule, however, is well known. Reversal of net potassium transport as one descends from the cortical to the medullary collecting tubule may account for this variability-secretion predominating in the cortical segment, reabsorption in the medullary segment. The key factor which determines the overall result may be the fluid flow rate $(12,13,35)$. Under circumstances of high urinary potassium excretion and low urinary flow, the potassium concentration in collecting tubule fluid would reach very high levels in the absence of potassium reabsorption by the medullary collecting tubule, as pointed out by Reineck et al. (35).

Further investigations are necessary to assess the importance of this phenomenon.

\section{ACKNOWLEDGMENTS}

The authors are grateful to Ms. Mary Fisher and Mr. Michael Leach for their technical assistance, to Ms. Margaret Hamilton for her secretarial assistance, and to Doctors Gerhard Giebisch, Roy Maffly, Bryan Myers, and Michael Weiner for criticizing the manuscript. We are also indebted to Dr. Clement A. Stone from the Merck Institute for Therapeutic Research, West Point, Pa., for a generous supply of amiloride, and to Doctors Frank Epstein and David Maddox for their assistance in the preparation of the different diets.

This study was supported by a research grant from the National Institutes of Health (AM 18077) and by a grant-in-aid from the American Heart Association (72821), with funds contributed in part by the Bay Area Heart Association.

\section{REFERENCES}

1. Jamison, R. L., F. B. Lacy, J. P. Pennell, and V. M. Sanjana. 1976. Potassium secretion by the descending limb or pars recta of the juxtamedullary nephron in vivo. Kidney Int. 9: 323-332.

2. Wright, F. S. 1974. Potassium transport by the renal tubule. In Kidney and Urinary Tract Physiology. K. Thurau, editor. Butterworth \& Co., Ltd., Scarborough, Ontario. 6(Series I): 79-106.

3. Giebisch, G. 1975. Some reflections on the mechanisms of renal tubular transport. Yale J. Biol. Med. 48: 315-336.

4. Jamison, R. L. 1970. Micropuncture study of superficial and juxtamedullary nephrons in the rat. Am. J. Physiol. 218: 46-55.

5. Johnston, P. A., C. A. Battilana, F. B. Lacy, and R. L. Jamison. 1977. Evidence for a concentration gradient favoring outward movement of sodium from the thin loop of Henle. J. Clin. Invest. 59: 234-240.

6. Stein, J. H., R. W. Osgood, and R. T. Kunau. 1976. Direct measurement of papillary collecting duct sodium transport in the rat. J. Clin. Invest. 58: 767-773.

7. Jamison, R. L. 1968. Micropuncture study of segments of thin loop of Henle in the rat. Am.J. Physiol. 215: 236-242.

8. Sanjana, V. M., P. A. Johnston, W. M. Deen, C. R. Robertson, B. M. Brenner, and R. L. Jamison. 1975. Hydraulic and oncotic pressure measurements in the inner medulla of the mammalian kidney.Am.J. Physiol. 228: 1921-1926.

9. Snedecor, G. W., and W. G. Cochran. 1967. Statistical Methods. Iowa State University Press, Ames, Iowa. 6th edition. 95.

10. Grantham, J. S. 1976. Renal transport and excretion of potassium. In The Kidney. B. M. Brenner and F. C. Rector, Jr., editors. W. B. Saunders Company, Philadelphia, Pa. 299-317.

11. Tannen, R. L., editor. 1977. Potassium homeostasis. Kidney Int. 11: 389-515.

12. Khuri, R. N., M. Wiederholt, N. Strieder, and G. Giebisch. 1975. Effects of flow rate and potassium intake on distal tubular potassium transfer. Am. J. Physiol. 228: 12491261.

13. Kunau, R.T., H. L. Webb, and S. L. Borman. 1974. Characteristics of the relationship between the flow rate of tubular fluid and potassium transport in the distal tubule of the rat. J. Clin. Invest. 54: 1488-1495.

14. Maddox, D. A., D. C. Price, and F. C. Rector. 1977. Effects of surgery on plasma volume and salt and water excretion in the rat. Am. J. Physiol. 233: F600-F606.

15. Battilana, C. A., D. R. Gelbart, F. B. Lacy, and R. L. Jamison. 1977. Effect of anesthesia on the hematocrit of rats prepared for micropuncture. Clin. Res. 25: 426A. (Abstr.)

16. Weiner, M. W., E. J. Weinman, M. Kashgarian, and J. P. Hayslett. 1971. Accelerated reabsorption in the proximal tubule produced by volume depletion. J. Clin. Invest. 50: $1379-1385$.

17. Berliner, R. W. 1961. Renal mechanisms for potassium excretion. Harvey Lect. 55: 141-171.

18. Malnic, G., R. M. Klose, and G. Giebisch. 1964. Micropuncture study of renal potassium excretion in the rat. Am. J. Physiol. 206: 674-686.

19. Kriz, W. 1967. Der Architektonische und funktionelle Aufbau der Rattenniere. Z. Zellforsch. Mikrosk. Anat. 82: 495-535.

20. Diezi, J., P. Michoud, J. Aceves, and G. Giebisch. 1973. Micropuncture study of electrolyte transport across the papillary collecting duct of the rat. Am. J. Physiol. 224: 623-634.

21. Stoner, L. C., M. B. Burg, and J. Orloff. 1974. Ion transport in cortical collecting tubule; effect of amiloride. Am. J. Physiol. 227: 453-459.

22. Duarte, C. G., F. Chomety, and G. Giebisch. 1971. Effect of amiloride, ouabain, and furosemide on distal tubular function in the rat. Am. J. Physiol. 221: $632-640$.

23. Meng, K. 1975. Comparison of the local effects of amiloride hydrochloride on the isotonic fluid absorption in the distal and proximal convoluted tubule. Pflügers Arch. Eur. J. Physiol. 357: 91-99.

24. Deetjen, P. 1969. The localization of transport processes in the nephron and their inhibition by diuretic agents as analyzed by micropuncture techniques. In Renal Transport and Diuretics. K. Thurau, H. Jahrmäker, editors. Springer-Verlag New York, New York. 215-226.

25. Stein, J. H., H. J. Reineck, and R. W. Osgood. 1977. Distal nephron potassium $(K)$ transport in the rat: effect of amiloride. Proc. Int. Union Physiol. Sci. 13: 717. (Abstr.)

26. Imai, M., and J. P. Kokko. 1974. Sodium chloride, urea, and water transport in the thin ascending limb of Henle. J. Clin. Invest. 53: 393-402.

27. Marsh, D. J., and C. M. Martin. 1977. Origin of electrical PD's in hamster thin ascending limbs of Henle's loop. Am. J. Physiol. 232: F348-F357.

28. Burg, M. B., and J. E. Bourdeau. 1978. Function of the 
thick ascending limb of Henle's loop. In New Aspects of Renal Function. K. J. Ullrich and H. G. Vogel, editors. Excerpta Medica, Amsterdam. 91-102.

29. Grantham, J. J., M. B. Burg, and J. Orloff. 1970. The nature of transtubular $\mathrm{Na}$ and $\mathrm{K}$ transport in isolated rabbit renal collecting tubules. J. Clin. Invest. 49: 1815-1826.

30. Hierholzer, K. 1961. Secretion of potassium and acidification in collecting duct of mammalian kidney. Am. J. Physiol. 201: 318-324.

31. Silva, P., B. D. Ross, A. N. Charney, A. Besarab, and F. H. Epstein. 1975. Potassium transport by the isolated perfused kidney. J. Clin. Invest. 56: 862-869.
32. Silva, P., R. S. Brown, and F. H. Epstein. 1977. Adaptation to potassium. Kidney Int. 11: 466-475.

33. Malnic, G., M. de Mello Aires, and G. Giebisch. 1971. Potassium transport across renal distal tubules during acid-base disturbances. Am. J. Physiol. 221: 1192-1208.

34. Wright, F. S., N. Streider, N. B. Fowler, and G. Giebisch. 1971. Potassium secretion by the distal tubule after potassium adaptation. Am. J. Physiol. 221: 437-448.

35. Reineck, N. J., R. W. Osgood, T. F. Ferris, and J. H. Stein. 1975. Potassium transport in the distal tubule and collecting tubule of the rat. Am. J. Physiol. 229: 14031409. 